\title{
Sexually distinct song \\ 2. cultures in a songbird \\ 3 metapopulation
}

4 Wesley H. Webb ${ }^{*}$, Michelle M. Roper ${ }^{1}$, Matthew D. Pawley ${ }^{1}$, Yukio Fukuzawa ${ }^{1}$, Aaron M.

$5 \quad$ Harmer $^{1}$, Dianne H. Brunton ${ }^{1}$

6

7

8

9

10

11

12

13

14

15

16

${ }^{1}$ School of Natural and Computational Sciences, Massey University, Auckland, New Zealand

*Corresponding author. Email wesleythewebb@gmail.com

Keywords: Female song, dialects, cultural evolution, birdsong, avian, bioacoustics 


\section{Abstract}

Songbirds learn their songs culturally, through imitating tutors. The vocal culture of a songbird population changes as new song units (syllables) are introduced through immigration, copying errors, and innovation, while other syllables fall out of use. This leads to a diversification of the syllable pool across the species, much like the diversification and spatial patterns of human language. Vocal cultures have been well studied in male songbirds but have been largely overlooked in females. In particular, few studies compare spatial variation of male and female song cultures. Here we undertake one of the first comparisons of male and female song culture in birds, analysing song data from a metapopulation of New Zealand bellbirds Anthornis melanura, spanning an archipelago of six islands. Having classified 20,700 syllables, we compare population syllable repertoire sizes and overlap between sites and sexes. We show that males and females-both with complex songs-have distinct song cultures, sharing only $6-26 \%$ of syllable types within each site. Furthermore, male and female syllable types can be statistically discriminated based on acoustic properties. Despite diverse syllable repertoires within sites, few syllable types were shared between sites (both sexes had highly distinct site-specific dialects). For the few types shared between sites, sharing

34 decreased with distance only for males. Overall, there was no significant difference between sexes in degree of site-site repertoire overlap. These results suggest different cultural processes at play for the two sexes, underlining the inadequacy of male-centric song research and calling for comparisons of male and female song cultures in many more species. 


\section{Introduction}

40 Culture is shared information or behaviour acquired through social learning from 41 conspecifics (Dawkins, 1976), involving the transmission of memes (units of culture) by 42 behavioural imitation. Vocal culture-the social learning of acoustic memes-has so far 43 been observed in songbirds (oscines; Passeri), some suboscines (Procnias spp., 44 Cotingidae), parrots, hummingbirds, cetaceans, elephants, seals, bats, and humans (Paton et al., 1981; Baptista and Schuchmann, 1990; Janik and Slater, 1997; Poole et al., 2005; Sanvito et al., 2007; Catchpole and Slater, 2008; Kroodsma et al., 2013). In these taxa, the vocal repertoire of a population changes as new memes are introduced through immigration, copying errors, and innovation, while other memes fall out of use (Catchpole and Slater, 2008). This leads to a diversification of the meme pool across the species, much like the diversification of human language-resulting in dialects (Podos and Warren, 2007).

Despite the high volume of studies on male birdsong culture and dialects (Jenkins, 1978; Whitehead and Rendell, 2014; Aplin, 2019), little is known about female song culture. This is partly due to a northern-hemisphere-biased view of sexual selection that emphasises male-male competition and female choice in driving elaborate traits in males (Darwin, 1871), but which does not provide a framework for understanding elaborate female traits (Riebel et al., 2019). Female song (and other elaborate female traits) have been overlooked as non-functional aberrations, resulting 'accidentally' from shared genetic architecture with males (Darwin, 1871; Lande, 1980; see Tobias et al., 2012 for review). This view has now been roundly discounted. Female song is present in $64 \%$ of surveyed songbird species (Webb et al., 2016), has been recovered as the ancestral state (Odom et al., 2014), can evolve independently of the male song phenotype (Price, 2015) and has 
63

female-specific functions in territory and resource defence, mate attraction, mate defence, and pair bonding (reviewed in Austin et al., 2021).

Overlooking females has impeded development of a more general theory that explains song culture in both sexes. For instance, the possibility that females have song cultures distinct from conspecific males, with different geographic patterns of song sharing, has hardly been investigated at a population level (Graham et al., 2017a).

Studies have reported a wide degree of sexual song dimorphism in songbirds, from identical repertoires for males and females at one extreme [e.g., forest weaver Symplectes bicolor (Wickler and Seibt, 1980), magpie lark Grallina cyanoleuca (Hall, 2000)], to completely non-overlapping repertoires at the other [e.g., many duetting wrens; (Brown and Lemon, 1979; Levin, 1996; Mann et al., 2009)]. However, studies comparing the sexes have mostly focused on within-pair repertoires in duetting species. To our knowledge, only four studies (of just two species) have compared spatial variation of male and female songs at a population level.

First, Mennill and Rogers (2006) examined the songs of duetting male and female eastern whipbird Psophodes olivaceus across their geographic range. While male whipbird song was highly consistent over space, female song showed pronounced variation, with multiple distinct song types. The authors suggest eastern whipbirds have undergone a decoupling of male and female song learning strategies in response to different sexspecific selection pressures.

Three later studies on rufous-and-white wrens (Graham et al., 2017a, 2018a, 2021) showed that song cultures of males and females can be similar in complexity, and appear to evolve in similar directions via acoustic adaptation and cultural drift. However, males and females differ in the relationship between dispersal distance and song-sharing with 
parents (Graham et al., 2017a), the speed of cultural change, and the relationship between immigration rate and cultural diversity (Graham et al., 2021).

We know of no other studies to examine spatial variation in song culture at a population level, comparing both sexes.

The New Zealand bellbird Anthornis melanura-hereafter 'bellbird'-provides an ideal system for comparing male and female song cultures over space. The bellbird is a nonduetting endemic honeyeater (Family Meliphagidae) with complex, geographically diverse song in both sexes, and probable open-ended learning (Roper, 2018). Bellbird populations occur across a network of islands and peninsulas in the Hauraki Gulf, northeastern New Zealand. Population connectivity is substantial, and regulated by geographic isolation (Baillie, 2011; Baillie et al., 2014). Females disperse more frequently than males, resulting in higher female connectivity between sites (as typical for songbirds: Greenwood, 1980; Clarke et al., 1997; Paris et al., 2016).

In this paper, we seek to advance understanding of female birdsong culture by comparing the patterns of male and female meme sharing across a network of six island and peninsula populations (Figure 1). Our questions are:

(1) Are there sexual differences in population syllable repertoire size?

(2) How much do male and female population repertoires overlap?

(3) What is the pattern of syllable type sharing between sites?

If geographic proximity drives cultural connectivity between islands, we expect sites that are closer together will share more memes (i.e., an isolation-by-distance pattern in vocal culture). We also expect higher female dispersal frequency will result in higher meme flow between sites, and thus higher sharing of syllable types between sites than for males. 

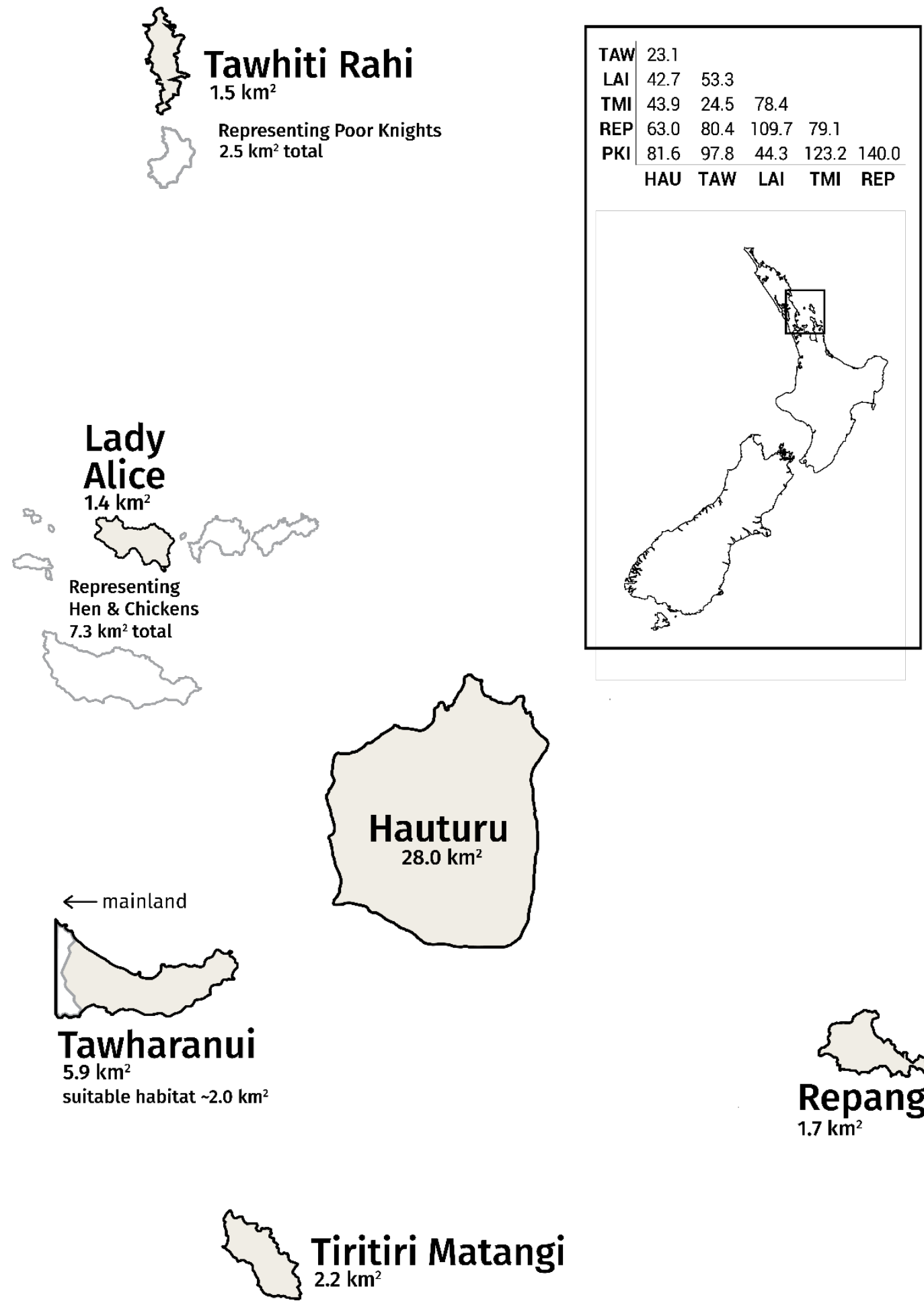

113 Figure 1-Simplified map of the Hauraki Gulf archipelago, home to a metapopulation of bellbirds.

114 Tawhiti Rahi represents the Poor Knights Islands group; likewise, Lady Alice Island represents the Hen 115 and Chickens Islands group. The other islands of these wider groups are shown in white. The distance 


\section{Methods}

\section{Creating the song database}

\section{Recording bellbird song}

122 Recording trips were conducted to six island and mainland peninsula sites in the Hauraki

123 Gulf 2013-2017 (Table 1), with iwi consent (Ngatiwai, Ngati Manuhiri) and permits from

124 the New Zealand Department of Conservation (47948-FAU, 34833-FAU, 41756-FAU,

125 48000-FAU) and Massey University Animal Ethics Committee (permit number 15/21).

126 The sites were chosen based on their large bellbird populations (good return for sampling

127 effort) and their variety in connectivity. A team of 1-5 recordists per site collectively spent

128 a total of over 1,000 recordist-hours actively tracking and recording wild bellbirds (per

129 site: Tawhiti Rahi, 108; Lady Alice, 110; Hauturu, 140; Tawharanui, 132; Repanga, 260;

130 Tiri, many hundreds of hours), with Marantz PMD661 portable solid-state recorders

131 paired with handheld Sennheiser ME-66 shotgun microphones. Recordists coordinated

132 movement to sample sites systematically and with maximal coverage, gathering 2,137

133 high-quality recorded songs (discrete vocalisation bouts) by adult individuals of known

134 sex, during daylight hours. During recording, metadata including identity, age and sex of

135 the focal bird was spoken into the microphone for later transcription. 


\section{Table 1-Geographic and sampling information for the six study sites.}

Tawhiti Rahi represents the larger Poor Knights Islands group; likewise, Lady Alice Island represents the larger Hen \& Chickens Islands group. Elevation data is from www.topomap.co.nz. In the Sample size column, $\mathrm{M}=$ male and $\mathrm{F}=$ female. Recording on Hauturu was restricted to an area $\sim 3 \mathrm{~km}{ }^{2}$.

\begin{tabular}{|c|c|c|c|c|c|}
\hline Sites & $\begin{array}{l}\text { GPS } \\
\text { Coordinates }\end{array}$ & Area $\left(\mathrm{km}^{2}\right)$ & Elevation & $\begin{array}{l}\text { Recording dates and number of } \\
\text { recordists }\end{array}$ & Sample size \\
\hline $\begin{array}{l}\text { Tawhiti Rahi } \\
\text { (representing Poor } \\
\text { Knights Island group) }\end{array}$ & $\begin{array}{l}35^{\circ} 28^{\prime} 06^{\prime \prime S} \\
174^{\circ} 44^{\prime} 13^{\prime \prime} \mathrm{E}\end{array}$ & $\begin{array}{l}1.5 \\
\text { (2.5 including } \\
\text { neighbouring } \\
\text { island, Aorangi) }\end{array}$ & $\begin{array}{l}191 \mathrm{~m} \\
\text { (216 m for } \\
\text { Aorangi) }\end{array}$ & $\begin{array}{l}\text { Single trip 23/02/2017-27/02/2017 } \\
3 \text { recordists }\end{array}$ & $\begin{array}{l}\text { Birds: } 128 \mathrm{M}, 48 \mathrm{~F} \\
\text { Songs: } 309 \mathrm{M}, 61 \mathrm{~F}\end{array}$ \\
\hline $\begin{array}{l}\text { Lady Alice (represents } \\
\text { larger Hen and Chickens } \\
\text { Islands group) }\end{array}$ & $\begin{array}{l}35^{\circ} 53^{\prime} 23^{\prime \prime S} \\
174^{\circ} 43^{\prime} 41^{\prime \prime} \mathrm{E}\end{array}$ & $\begin{array}{l}1.4(7.3 \\
\text { including entire } \\
\text { Hen and } \\
\text { Chickens group }\end{array}$ & $\begin{array}{l}158 \mathrm{~m} \\
\text { (417 m for } \\
\text { Hen) }\end{array}$ & $\begin{array}{l}\text { Single trip } 27 / 05 / 2015-30 / 05 / 2015 \\
4 \text { recordists }\end{array}$ & $\begin{array}{l}\text { Birds: } 149 \mathrm{M}, 116 \mathrm{~F} \\
\text { Songs: } 181 \mathrm{M}, 126 \mathrm{~F}\end{array}$ \\
\hline Hauturu & $\begin{array}{l}36^{\circ} 11^{\prime} 57^{\prime \prime} \mathrm{S} \\
175^{\circ} 04^{\prime} 53^{\prime \prime} \mathrm{E}\end{array}$ & 28.0 & $722 \mathrm{~m}$ & $\begin{array}{l}\text { Single trip 05/04/2016-09/04/2016 } \\
4 \text { recordists }\end{array}$ & $\begin{array}{l}\text { Birds: } 57 \mathrm{M}, 63 \mathrm{~F} \\
\text { Songs: } 67 \mathrm{M}, 98 \mathrm{~F}\end{array}$ \\
\hline Tawharanui & $\begin{array}{l}36^{\circ} 22^{\prime} 20^{\prime \prime S} \\
174^{\circ} 50^{\prime} 30^{\prime \prime} \mathrm{E}\end{array}$ & 5.9 & $91 \mathrm{~m}$ & $\begin{array}{l}\text { 20/04/2016, 18/08/2016, } \\
\text { 01/09/2016-07/09/2016, 22/09/2016 } \\
1-3 \text { recordists }\end{array}$ & $\begin{array}{l}\text { Birds: } 66 \text { M, } 26 \text { F } \\
\text { Songs: } 206 \text { M, } 37 \text { F }\end{array}$ \\
\hline Repanga & $\begin{array}{l}36^{\circ} 26^{\prime} 11^{\prime \prime S} \\
175^{\circ} 46^{\prime} 16^{\prime \prime} \mathrm{E}\end{array}$ & 2.0 & $214 \mathrm{~m}$ & $\begin{array}{l}\text { Single trip 03/11/2016-09/11/2016 } \\
5 \text { recordists }\end{array}$ & $\begin{array}{l}\text { Birds: } 122 \mathrm{M}, 141 \mathrm{~F} \\
\text { Songs: } 328 \mathrm{M}, 196 \mathrm{~F}\end{array}$ \\
\hline Tiritiri Matangi & $\begin{array}{l}36^{\circ} 36^{\prime} 01^{\prime \prime S} \\
174^{\circ} 53^{\prime} 24^{\prime \prime} \mathrm{E}\end{array}$ & 2.2 & $80 \mathrm{~m}$ & $\begin{array}{l}\text { Frequent recordings in } \\
\text { non-winter months } 2013-2015 \\
1-2 \text { recordists }\end{array}$ & $\begin{array}{l}\text { Birds: } 91 \mathrm{M}, 58 \mathrm{~F} \\
\text { Songs: } 389 \mathrm{M}, 138 \mathrm{~F}\end{array}$ \\
\hline
\end{tabular}




\section{Segmenting songs into syllables}

137 Songs were imported into a database in Koe bioacoustics software (Fukuzawa et al., 2020)

138 and manually segmented into syllables by visually inspecting the spectrogram and setting

139 syllable start/end points. Bellbirds mostly sing in discrete units that are easy to demarcate 140 as syllables based on a gap either side. Occasionally there are fast-paced bursts where it

141 is not clear where one unit ends and another begins; in these cases sounds were grouped 142 together as a syllable if they were separated by less than $15 \mathrm{~ms}$ of silence. This value was 143 chosen through trial and error for the best consistency of syllable groupings.

\section{Classifying syllables}

145 To prepare for classification, the 20,700 segmented syllables were ranked by acoustic 146 similarity in Koe. Similarity was calculated by extracting all available acoustic features 147 for each unit and applying the UPGMA method (Sokal, 1958); see

148 https://github.com/fzyukio/koe/wiki for details of extracted features and similarity

149 index calculation.

150 WHW then compared syllables visually and aurally to classify them into types based on

151 just-noticeable differences in pitch, timbre, and duration of the playback and visual 152 appearance of the spectrogram. Manual perception-based classification is considered 153 excellent for acoustic classification (Sayigh et al., 2007; Duda et al., 2012) and allowed 154 finer scale than automated classification methods, such as multi-dimensional scaling 155 (MDS) or principal component analysis (PCA). The high acuity of bird hearing relative to 156 humans (Dooling, 2004) justifies a fine-scale classification approach. We validated our 157 classification by having 74 inexperienced judges independently label a subset of 158 syllables. Average match with our own labels was 89.6\% (median 95.6\%); see Fukuzawa 159 et al. (2020) and Article S1A for more details. 


\section{Sex differences in population-level repertoires}

161

162

163

164

165

\section{Male and female syllable diversity}

The raw number of syllable types recorded at each site are not directly comparable, due to the inevitable confounding of different sampling effort. To account for this, we used the statistical software EstimateS (Colwell, 2013) to produce syllable type accumulation curves and extrapolate the true number of syllable types at each site (Article S1B).

\section{Repertoire overlap of male and female population sectors}

For each site we calculated the percentage overlap between male and female population repertoires, using the Jaccard similarity index (Hamers et al., 1989): the number of shared types divided by the total number of types.

Next, the acoustic feature measurements of all syllables (previously extracted to aid classification in Koe) were normalised by mean-centering and dividing by standard deviation. To test whether male-only, female-only, and shared syllable types form three distinguishable clusters in acoustic space, we classified syllables using a linear discriminant analysis (LDA) on the data, with leave-one-out cross-validation. If male-only, female-only, and shared syllables are randomly interspersed in acoustic space, then the LDA classification results will be similar to random assignment of groups. If the three groups occupy more distinct ranges, then the LDA classification will perform much better than random assignment.

\section{The pattern of syllable type sharing between sites}

We calculated repertoire overlaps between sites, for all pairwise combinations of site lists_comparing males against males, females against females. For each sex we tested for an isolation-by-distance pattern in repertoire overlaps between sites, in two ways. 
183 First, we conducted a Hauturu-centric analysis. The large size, geographic centrality, and 184 the long-term persistence of the Hauturu bellbird population make it likely to be a 185 substantial source of dispersing bellbirds to other sites in the Hauraki Gulf archipelago.

186 We calculated Spearman's rank correlation coefficients between population repertoire overlap with Hauturu against geographic distance from Hauturu.

Next, to test for an overall isolation-by-distance pattern, we calculated Spearman's rank correlation coefficients between percentage of site-site repertoire overlap against site-site geographic distance, for all pairwise combinations of sites in the archipelago. In this case, to account for non-independence of points (being pairwise combinations), we used the

To test whether males or females share more syllables between sites overall, we used a

194 two-tailed Sign Test (Dixon and Mood, 1946), with null hypothesis: the degree of site-site 195 sharing is equal between sexes (Article S1C).

\section{Results}

\section{Sex differences in population repertoires}

\section{Male and female syllable diversity}

199 Across the metapopulation we recorded a total of 702 syllable types: 337 male-only, 203

200 female-only, and 162 shared. See Data S1 and Table S1 for a complete catalogue.

201 For each site and sex, the syllable type accumulation curve levelled off nearly or 202 completely by 500 songs (i.e., approximating the true number of syllable types present), 203 allowing meaningful comparison of syllable diversity (Figure S1). 
204 We found no evidence of a difference in repertoire size for males versus females within 205 sites; 95\% confidence intervals overlap for males and females in all cases (Table 2). There

206 was high variability between sites for both sexes, with male point estimates ranging from 20780 (Repanga) to 186 (Hauturu) and females from 81 (Repanga) to 186 (Hauturu).

\section{Repertoire overlap of male and female population sectors}

209 Male and female population sectors had largely separate repertoires, ranging from $6 \%$ 210 total units shared at Tawhiti Rahi to $26 \%$ shared at Hauturu (Figure 2, Table S2). In other 211 words, 74-94\% of syllable types at each site were sung by one sex only.

213 Table 2-Extrapolated estimates of male and female syllable diversity within sites.

214 Estimated number of syllable types at 500 songs, for male and female population sectors at each site.

215 Ninety-five-percent confidence intervals are in brackets. Calculated with the statistical software Estimate $216 S$ (Colwell, 2013).

\begin{tabular}{|c|c|c|}
\hline \multicolumn{3}{|l|}{ Site } \\
\hline & Male & Female \\
\hline Tawhiti Rahi & $\begin{array}{l}135(121-149) \\
n=306 \text { songs }\end{array}$ & $\begin{array}{l}119(68-169) \\
n=58 \text { songs }\end{array}$ \\
\hline Lady Alice & $\begin{array}{l}143(118-169) \\
n=181\end{array}$ & $\begin{array}{l}128(93-163) \\
n=125\end{array}$ \\
\hline Hauturu & $\begin{array}{l}186(139-234) \\
n=67\end{array}$ & $\begin{array}{l}186(151-220) \\
n=98\end{array}$ \\
\hline Tawharanui & $\begin{array}{l}116(103-129) \\
n=204\end{array}$ & $\begin{array}{l}89(48-130) \\
n=37\end{array}$ \\
\hline Repanga & $\begin{array}{l}80(72-89) \\
n=328\end{array}$ & $\begin{array}{l}81(65-97) \\
n=196\end{array}$ \\
\hline Tiri 2013, 2014, 2015 & $\begin{array}{l}165(152-178) \\
n=389\end{array}$ & $\begin{array}{l}145(115-175) \\
n=138\end{array}$ \\
\hline
\end{tabular}




\section{Syllable types}

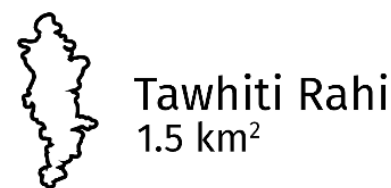

Representing

Poor Knights

$2.5 \mathrm{~km}^{2}$ total

Lady Alice

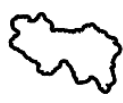
$1.4 \mathrm{~km}^{2}$

Representing

Hen \& Chickens

$7.3 \mathrm{~km}^{2}$ total

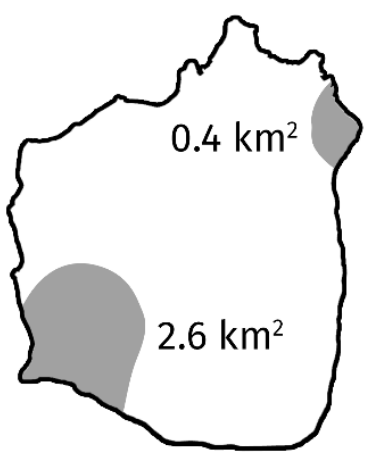

Hauturu

$28.0 \mathrm{~km}^{2}$

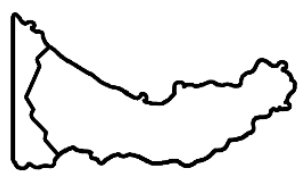

Tawharanui

$5.9 \mathrm{~km}^{2}$

Suitable habitat $\sim 2.0 \mathrm{~km}^{2}$

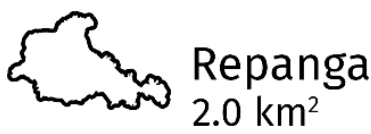

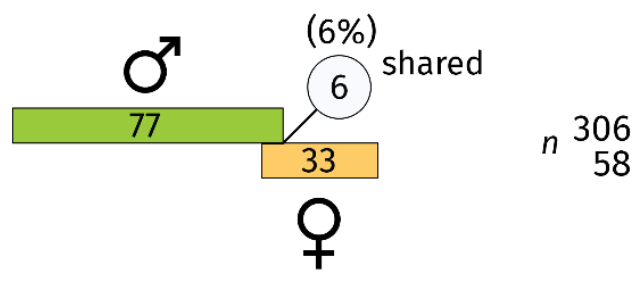

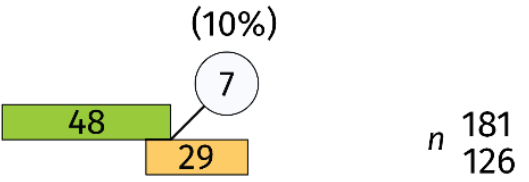

(26\%)

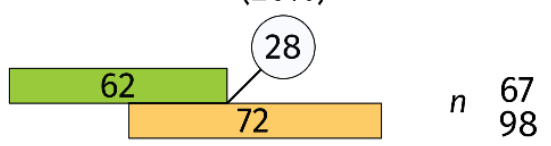

n 205

Tiri 2013,

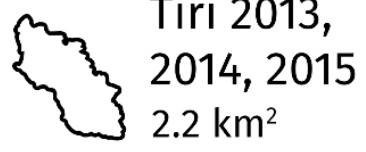

(8\%)

13
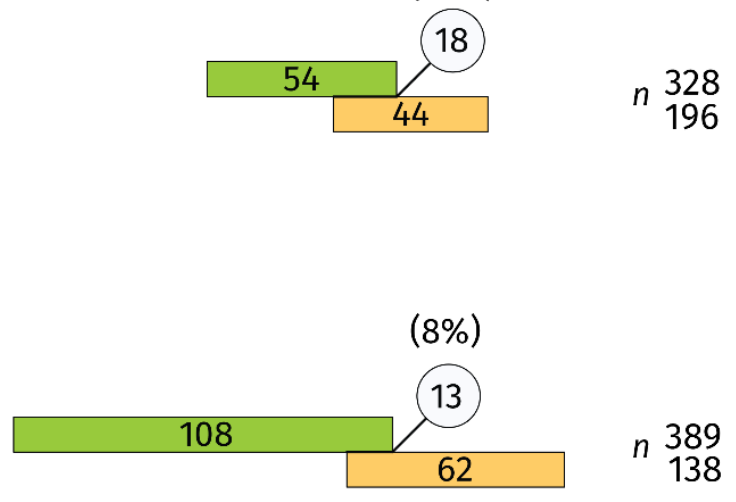
Figure 2-0verlap of male and female population syllable repertoires.

Each diagram indicates the recorded number of male (green bar) and female (orange bar) syllable types, and the number of types common to both sexes (circle). The percentage overlap is given above the circle, calculated as the Jaccard similarity index: number of shared types divided by total number of types. For robustness, repertoires exclude types with fewer than three occurrences within that site-and-sex group. Bar length is proportional to the number of syllable types, and overlap length is proportional to the number of shared syllable types. Sample sizes (number of songs) for the male and female bars are given to the right of the bars. Note that repertoire sizes are recorded values, not extrapolated, and therefore are not directly comparable due to differing sample sizes. However, relative overlap percentage is more robust to differing sample sizes and thus meaningful to compare. Site outlines on the left of the figure are to scale. The shaded grey area in the Hauturu outline indicates the sampled region of the island.

231 In the Linear Discriminant Analysis (LDA) ordination, male-only and female-only syllables form two clear, partially-overlapping clusters, with shared syllables in between, when data from all sites are pooled. For individual sites the configuration of the three clusters varies but shows a tendency for female-only syllables to occur at lower LD1 values, maleonly to occur at higher LD1 values, with shared syllables in between.

Success of the LDA leave-one-out classifier had an overall lift of 1.78; that is, the LDA assigned labels (male-only, female-only and shared) to syllables overall 1.78 times better than random allocation of labels. Lift was 1.51 for male-only syllables, 3.99 for femaleonly syllables, and 2.15 for shared syllables. P values for all lift tests were $<0.001$; i.e., in

240 all cases none of the 4999 null distributions had a lift as large as the observed lift.

241 Therefore, male-only, female-only, and shared types can be separated on the basis of acoustic features. 
bioRxiv preprint doi: https://doi.org/10.1101/2021.07.05.451205; this version posted July 27, 2021. The copyright holder for this preprint (which was not certified by peer review) is the author/funder. All rights reserved. No reuse allowed without permission.

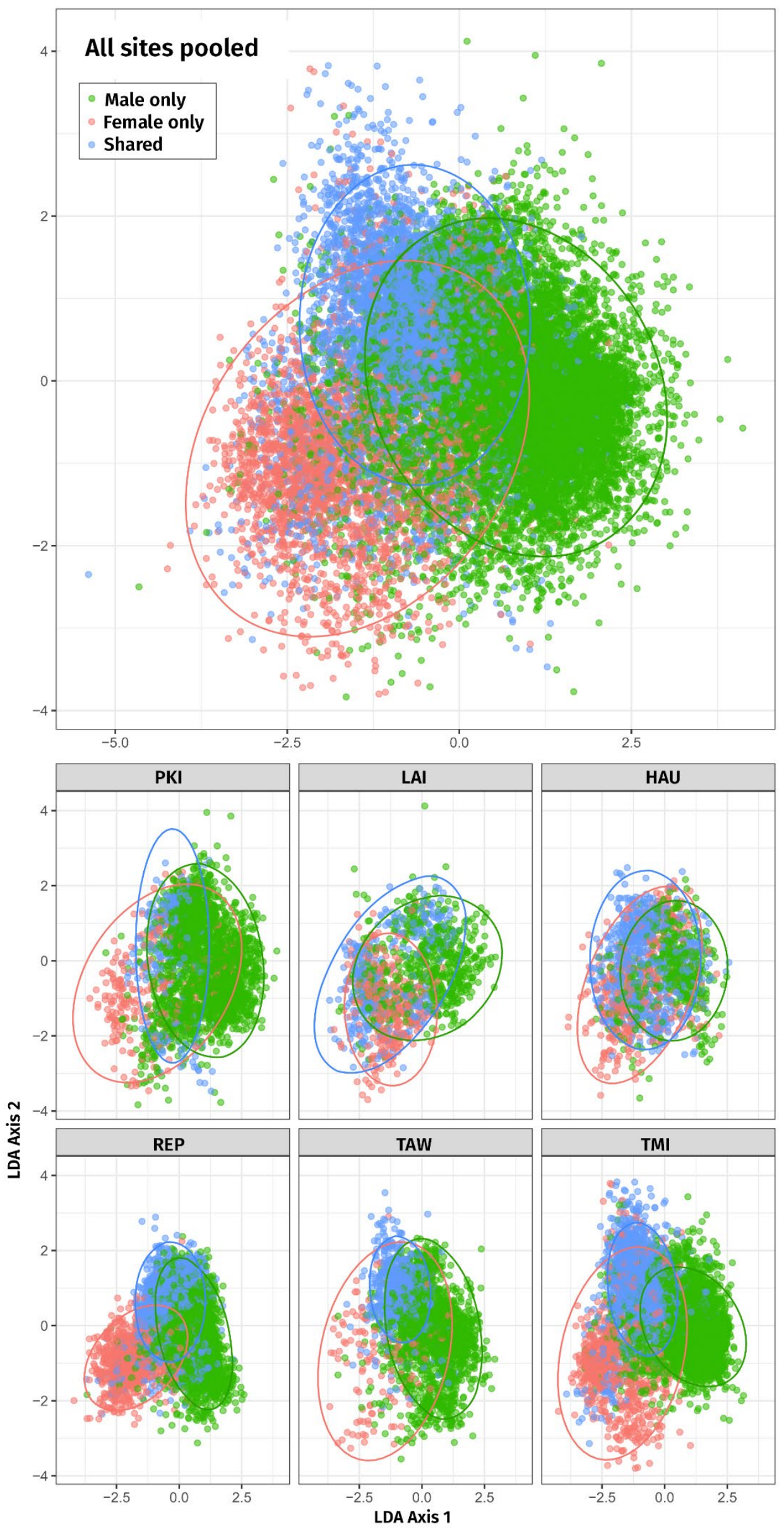


247 Figure 3-Two-dimensional linear discriminant analysis (LDA) of male-only, female-only, and

248 shared syllables for all sites combined (top) and each site separately (bottom).

249 Ellipses represent the regions covering 95\% of the data (according to the fitted normal). Each site is

250 plotted using the same axes to be comparable. Site abbreviations are as follows: PKI, Tawhiti Rahi,

251 representing Poor Knights Islands; LAI, Lady Alice Island, representing Hen \& Chickens; HAU, Hauturu;

252 REP, Repanga; TAW, Tawharanui; TMI, Tiri.

253

254

255 The pattern of meme sharing between sites

\section{Site-site repertoire overlap}

257 Matrices of site-site repertoire overlap are presented in Figure 4. The degree of site-site

258 repertoire overlap between male populations was low, ranging 3-18\% (median=6\%); for

259 females: 1-12\% (median=5\%). Remarkably, for both sexes, the syllable types shared

260 between sites were almost exclusively pure-tone whistle syllables or simple stutter-like

261 syllables. The one exception was Hauturu-Tawharanui, which additionally shared some

262 more complex types following the recent Hauturu $\rightarrow$ Tawharanui founder event (Brunton

263 et al., 2008). See Data S1 and Data S2.

264

265 


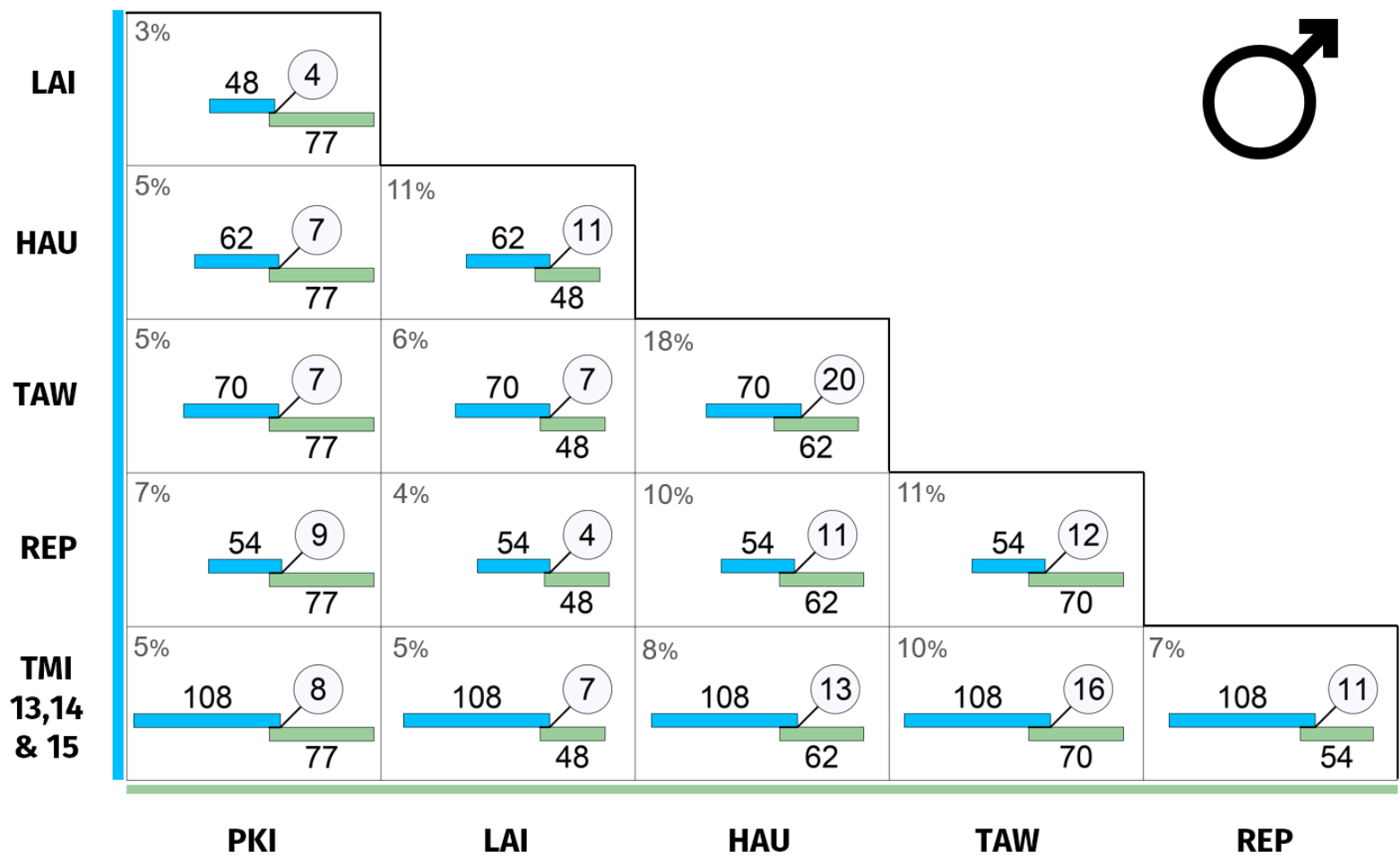

267

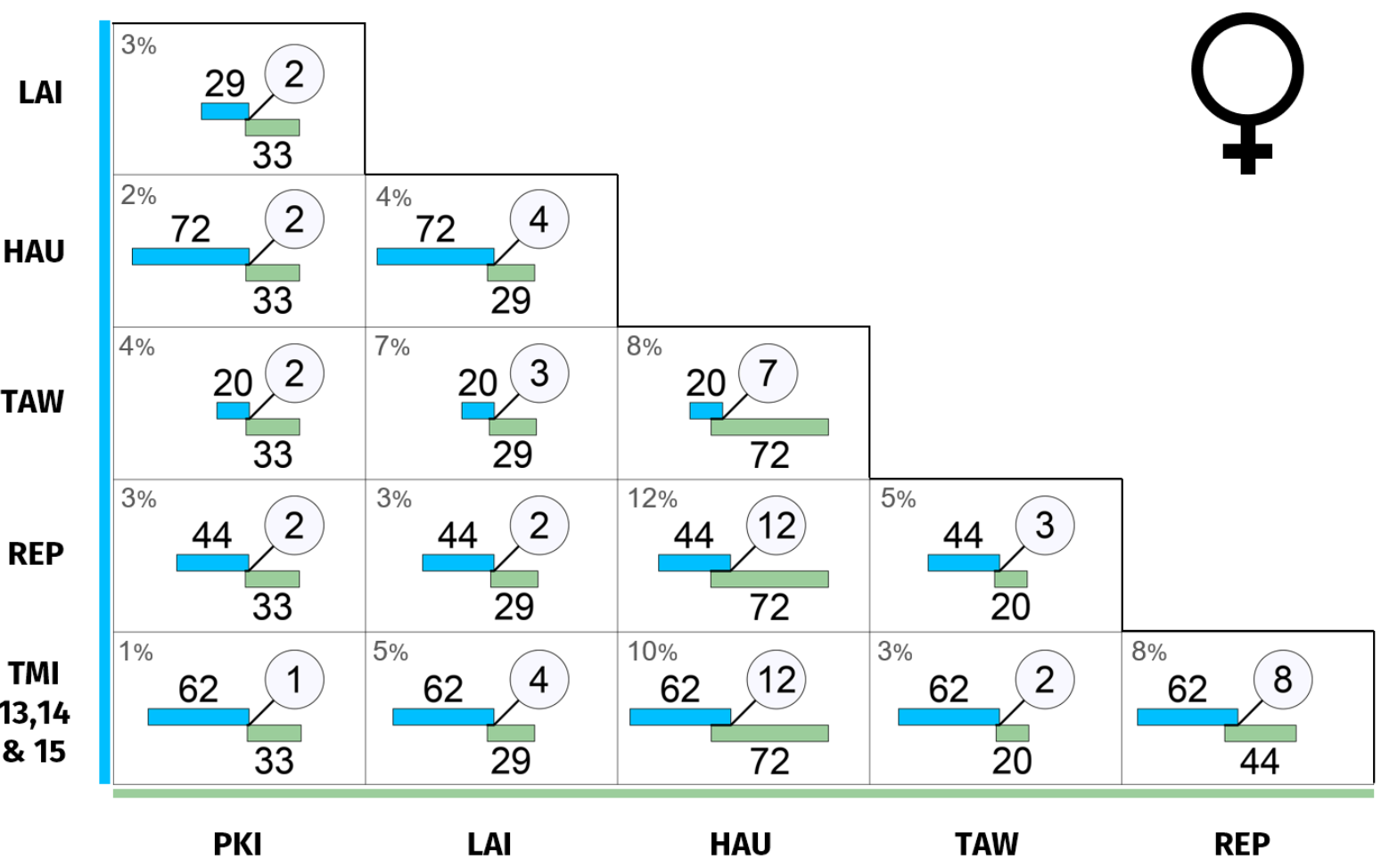


271 Figure 4-(Top) Male population repertoire overlap between sites. (Bottom) Female population 272 repertoire overlap between sites.

273 Each cell indicates the recorded number of syllable types for the two sites (blue and green bars), and the

274 number of types common to both (circle). The percentage overlap is given at the top left of each cell and is

275 calculated as Jaccard similarity index: number of shared types divided by total number of types. For

276 robustness, repertoires exclude types with fewer than three occurrences within that site and sex. Bar

277 length is proportional to the number of syllable types, and overlap length is proportional to the shared

278 number of syllable types. Site abbreviations are as follows: PKI, Tawhiti Rahi (representing Poor Knights

279 Islands); LAI, Lady Alice Island (representing Hen and Chickens); HAU, Hauturu; TAW, Tawharanui; REP,

280 Repanga; TMI, Tiri. 


\section{Repertoire overlap versus distance}

283 The relationship between repertoire overlap with Hauturu versus geographic distance

284 from Hauturu is shown in Figure 5A. There was a negative correlation between sharing 285 and distance for males $\left(\mathrm{r}_{\mathrm{s}}=-0.90, d f=3,0.03<\mathrm{P}<0.05\right)$ but no relationship for females $\left(\mathrm{r}_{\mathrm{s}}\right.$ $286=-0.10, d f=3, \mathrm{P}>0.10)$. Contrary to predictions, sites at increasing distances from Hauturu 287 did not share a progressively diminishing subset of syllable types with Hauturu, but 288 different (apparently unrelated) subsets; this was true for both males and females (Data 289 S2).

290 When considering sharing between all pairwise combinations of sites in the archipelago 291 (Figure 5B), we did not find evidence of an isolation-by-distance pattern, for males $(\rho=$ $292-0.525, \mathrm{P}=0.064)$ or females $(\rho=-0.525, \mathrm{P}=0.076)$.

293 The recent founder event, where bellbirds from Hauturu colonised Tawharanui (Brunton 294 et al., 2008) could possibly inflate the degree of sharing between the two sites, compared 295 to other sites where both populations are well established. Therefore we tested 296 robustness of the correlations to removal of the Hauturu-Tawharanui datapoint, but 297 found little change in the slope or strength of the correlations.

298 There was no evidence of an overall difference between males and females in the degree 299 of site-site repertoire overlap; out of 15 site-site comparisons, males shared a higher 300 percentage of syllables than females in 9 cases, lower in 4 cases, and equal in two cases 301 (Sign Test $\mathrm{P}=0.17$ ). 

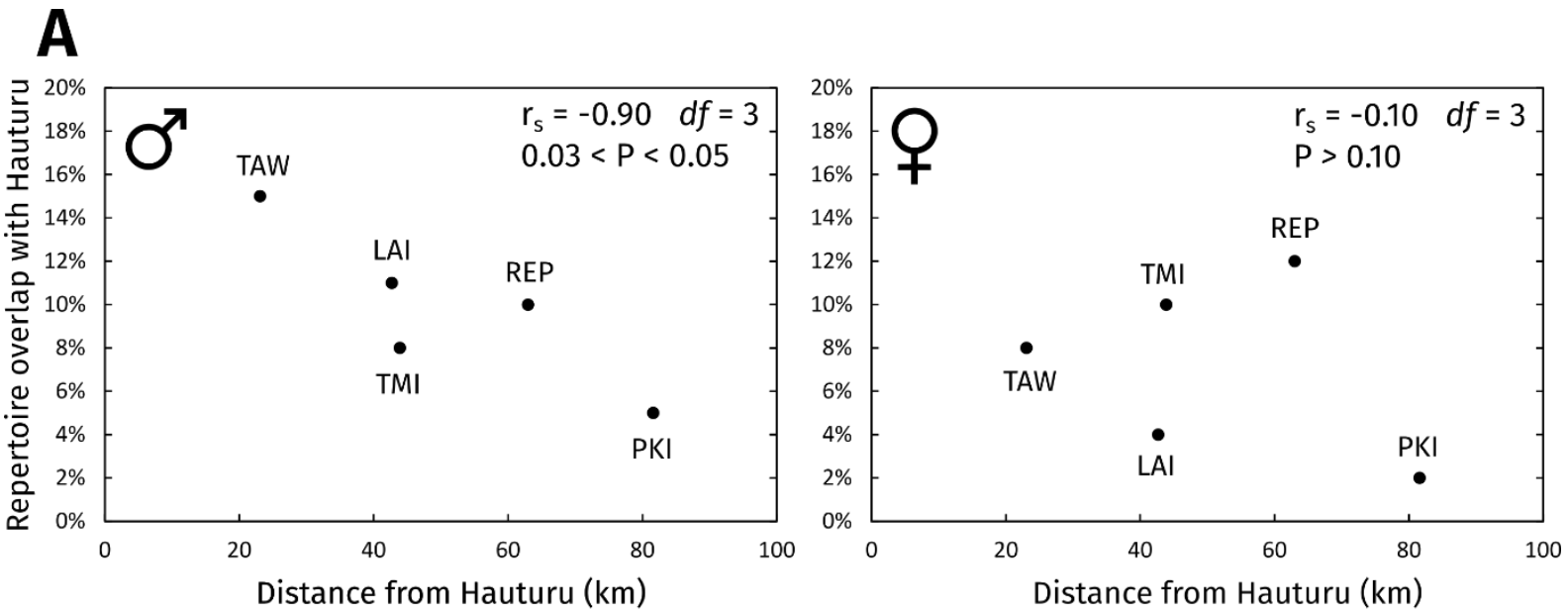

\section{B}

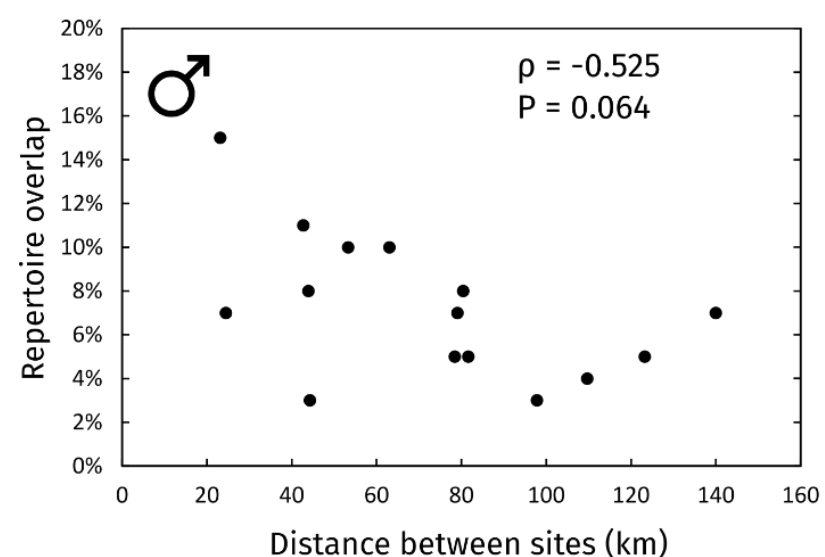

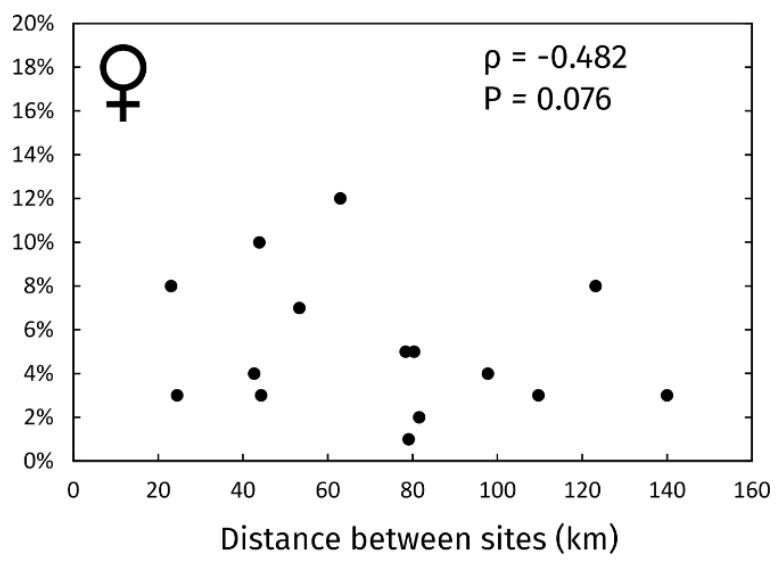

306 Figure 5-Repertoire overlap versus distance between sites.

307 (A) Repertoire overlap of all subpopulations with Hauturu versus their distance from Hauturu. Overlaps

308 were calculated on repertoire lists of types with 3+ occurrences within each site-and-sex group. Site

309 abbreviations: TAW, Tawharanui; LAI, Lady Alice Island (representing Hen and Chickens); TMI, Tiri; REP,

310 Repanga; PKI, Tawhiti Rahi (representing Poor Knights Islands). (B) Site-site repertoire overlap versus

311 site-site geographic distance, for all pairs of sites. Spearman's rank correlation coefficients $\left(\mathrm{r}_{\mathrm{s}}\right)$ were

312 calculated using the RELATE routine in PRIMER (version 7) with 9999 permutations, accounting for the

313 non-independence of points. 


\section{Discussion}

318 This is one of the first comparisons of male and female song cultures across a 319 metapopulation (Mennill and Rogers, 2006; Graham et al., 2018a, 2018b, 2021). We found 320 that male and female bellbirds have comparable repertoire sizes (at a population level;

321 Table 2), and sexually distinct vocal cultures, sharing only a small percentage of syllable 322 types between sexes (6-26\% within each site; Figure 2). Whether a type is male-specific, 323 female-specific, or shared between sexes can be predicted based on its acoustic properties 324 (Figure 3). Furthermore, song cultures of both sexes differ dramatically between sites325 demonstrating male and female song dialects (Figure 4, Data S1). Despite a large and 326 varied repertoire within sites, generally the only types shared between sites were flat327 contour, pure-tone whistle syllables (Article S1A) or simple stutter-like syllables. 328 Between-site sharing of these syllable types decreased with distance for males but not 329 females. These contrasting patterns of sharing across the archipelago may result from sex differences in dispersal, meme mutation rates and song-learning modes.

331 Comparisons of male and female repertoire sizes typically focus on individual-level

332 repertoires. Such studies have found smaller female repertoires in some cases (e.g., 333 rufous-and-white wrens Thryophilus rufalbus, Mennill and Vehrencamp, 2005; banded 334 wrens Thryophilus pleurostictus, Hall et al., 2015), equal-sized repertoires in other cases 335 (e.g., bay wren Thryothorus nigricapillus, Levin, 1996), and at least one case of larger 336 female repertoire size (stripe-headed sparrow Peucaea $r$. ruficauda, Illes, 2014). The 337 drivers of individual repertoire size are thought to differ between sexes, with males under 338 selection from male-male competition and female choice (Catchpole, 1987; Hill et al., 339 2018), and females perhaps primarily from female-female competition for non-sexual 340 breeding resources (Tobias et al., 2012). In the present study, similar male and female 
341 repertoire sizes may be explained by bellbird social ecology. Bellbirds are socially 342 monogamous, and both sexes are highly social and aggressive in singing interactions

343 (Roper, 2018). It is plausible, therefore, that similar intensity of competition and social

344 interaction drive the evolution of similar syllable diversity in the two sexes. However, our 345 analysis is on population-level repertoires, which are a product of both individual 346 repertoire sizes and variation between individuals. For example, equal male and female 347 population repertoire sizes could also result if male individual repertoires are larger and 348 more consistent between individuals (cultural conformity; Aplin et al., 2015), and females 349 smaller and more variable (cultural non-conformity; Riebel et al., 2015). Additional 350 focused recording of banded individuals is required to quantify these two sources of 351 diversity.

352 It is interesting that population repertoire sizes varied greatly between sites. Adaptation 353 to differing acoustic environments (Potvin and Clegg, 2015; Graham et al., 2017b) seems 354 an unlikely explanation, as all sites were coastal, with similar vegetation (though 355 soundscape was not measured). Another potential explanation is that genetic diversity 356 has driven population repertoire size. However, sites with low genetic diversity (Baillie, 357 2011) did not have correspondingly low syllable diversity, suggesting song culture is not 358 tightly constrained by genetic diversity in bellbirds (see also Graham et al., 2018). We 359 suspect that between-site differences in repertoire size are more likely driven by 360 competition level. For example, sites with higher population density may have elevated 361 competition for food, or sites with high population connectivity may experience increased 362 competitive encounters with migrants—selecting for bigger individual repertoires.

363 The discovery of sexually distinct, yet partly overlapping syllable repertoires raises 364 questions about transmission and function. Logically, all sex-specific syllable types must 
365 be learnt male-to-male or female-to-female (as in rufous-and-white wrens, for example;

366 Mennill and Vehrencamp, 2005). But what of types common to both sexes? These must

367 reflect inter-sexual learning in some form, whether accidental or intentional (Evans and

368 Kleindorfer, 2016). Once learnt inter-sexually, these memes could be transmitted intra-

369 sexually and become an established part of the repertoire for that sex. Roper et al. (2018)

370 found that juvenile male and female bellbird song is spectrally similar, then diverges prior

371 to crystallisation. Perhaps both sexes of bellbird are physiologically capable of

372 overlapping in acoustic space, but other factors (e.g., learning strategies, sexual/social

373 selection) prevent it in the wild. This appears true in slate-coloured boubous Laniarius

374 funebris; male and female boubous share no syllable types in the wild, but birds hand-

375 raised under experimental conditions develop syllables of both sexes (Wickler and Seibt,

376 1988). Wild birds may choose to express sex-specific memes to help avoid being mistaken

377 for the other sex, which risks attracting same-sex rivals or repelling potential mates

378 (Logue et al., 2007). However, the benefit of shared syllables is unclear. Might sex-specific

379 syllables function in intra-sexual communication, and shared syllables in inter-sexual communication? Sophisticated field experiments with banded individuals are needed to resolve meme functions and transmission modes in bellbirds.

We found that male-specific and female-specific syllables do occupy two largely distinct

383 regions of acoustic space, with shared syllables occupying a cluster between in a 'sex-

384 neutral' range (Figure 3). In the ordination, the separation of male-specific and female-

385 specific memes could be due to universal morphological constraints of body size and 386 syrinx structure, as males are 20\% larger than females (Heather and Robertson, 2000) 387 and have different syrinx morphologies (Roper, 2018). At the same time, the spread and 388 shape of the clusters vary widely between sites, which may reflect site-specific cultures. 

was not strongly related to geographic proximity between islands; only males showed

391 some evidence of isolation with distance from Hauturu (Figure 5). However, for both 392 sexes the percentage of syllable types shared between sites was small, and almost totally

393 limited to pure-tone whistle syllables and simple stutter-like syllables (except for 394 Hauturu-Tawharanui, which shared more types, likely due to the recent founder event 395 described in Brunton et al., 2008). The observed pattern suggests that immigrants 396 abandon most source memes after arrival, retaining only pure-tone and stutter-like types. 397 Perhaps all but these simple types incur high aggression at new sites ('colony password' 398 hypothesis; Feekes, 1977) and so are dropped in favour of the local dialect.

399 The large size and geographic centrality of the Hauturu population make it a likely source 400 of dispersing bellbirds to other sites in the archipelago. Thus, one might expect the islands 401 around Hauturu to form a chain of 'stepping stones' for bellbird dispersal, leading to progressively more dissimilar repertoires away from the central source population. There 403 are many examples of such chains (Irwin et al., 2005; Parker et al., 2012; Lachlan et al., 404 2013). In contrast, we found that for both male and female bellbirds, sites at increasing 405 distances from Hauturu did not share a progressively diminishing subset of syllable types 406 with Hauturu, but different (apparently unrelated) subsets (Data S2). Therefore, our 407 results suggest direct dispersal to each site from Hauturu, rather than serial dispersal 408 along the island chain.

409 We predicted that female-biased dispersal in bellbirds should result in higher female 410 meme flow and thus higher inter-site sharing for females than for males. Instead, we 411 found no evidence for a sexual difference in amount of sharing between sites. That females 412 do not show higher inter-site sharing suggests that other processes-such as a higher 
413 turnover rate or weaker retention of source memes-counteract the greater connectivity

414 of females between sites.

415 Large-scale studies of song culture in the wild are challenging. In contrast to a laboratory 416 situation, it is difficult to amass data, the identity of individuals is not known, and there is 417 little control over the social context of singing-which limits assessment of individual418 level mechanisms. However, our population-level analyses reveal distinct and complex 419 female culture with different spatial patterns to male culture. This underlines the 420 inadequacy of the male-centric research paradigm and calls for comparisons of male and

421 female repertoires in many more species (Riebel et al., 2019). Sophisticated field 422 experiments are now needed to resolve the mechanisms of dispersal, selection and 423 learning modes that give rise to the pattern we have uncovered.

\section{Author contributions}

427 Dianne Brunton and Wesley Webb conceived of the study. Wesley Webb, Michelle Roper,

428 Dianne Brunton, and Aaron Harmer conducted the fieldwork with help from volunteers. 429 Wesley Webb, Yukio Fukuzawa, and Michelle Roper created the song database. Wesley 430 Webb, Yukio Fukuzawa and Matthew Pawley analysed the data, with guidance from 431 Dianne Brunton and Aaron Harmer. Wesley Webb wrote the paper with guidance from 432 the other authors. 


\section{Data availability}

434 The interactive Koe database can be accessed online at koe.io.ac.nz with username

435 korimako and password Bellbird_Culture. See Data S3 for a table of all acoustic units and annotations, and Data S4 for a table of all songs and their metadata. Measurements of all syllables can be accessed at 10.5281/zenodo.5072580.

\section{Acknowledgements}

We thank Ngati Wai and Ngati Manuhiri iwi for their support, and Barbara Evans, Jessica

Patino-Perez, and Mehrnaz Tavasoli for their help with recording song. The research was

funded by a Marsden Fund grant (13-MAU-004) from the Royal Society of New Zealand

Te Apārangi. The manuscript was improved by feedback from Rebecca Webb.

\section{References}

Aplin, L. M. (2019). Culture and cultural evolution in birds: a review of the evidence. Anim. Behav. 147, 179-187. doi:10.1016/j.anbehav.2018.05.001.

Aplin, L. M., Farine, D. R., Morand-Ferron, J., Cockburn, A., Thornton, A., and Sheldon, B. C. (2015). Experimentally induced innovations lead to persistent culture via conformity in wild birds. Nature 518, 538-541. doi:10.1038/nature13998.

Austin, V. I., Dalziell, A. H., Langmore, N. E., and Welbergen, J. A. (2021). Avian vocalisations: the female perspective. Biol. Rev. 96, 1484-1503. doi:10.1111/brv.12713.

Baillie, S. M. (2011). Population genetics, biogeography and ecological interactions of the New Zealand bellbird (Anthornis melanura) and their avian malaria parasites: a thesis presented in partial fulfilment of the requirements for the degree of Doctor of Philosophy (Ph. D.) in Zoology at Massey University, Albany, New Zealand. Available at: http://muir.massey.ac.nz/handle/10179/2863 [Accessed July 18, 2014]. 
Baillie, S. M., Ritchie, P. A., and Brunton, D. H. (2014). Population genetic connectivity of an endemic New Zealand passerine after large-scale local extirpations: a model of re-colonization potential. Ibis 156, 826-839. doi:10.1111/ibi.12182.

Baptista, L. F., and Schuchmann, K.-L. (1990). Song learning in the Anna hummingbird (Calypte anna). Ethology 84, 15-26.

Brown, R. N., and Lemon, R. E. (1979). Structure and evolution of song form in the wrens Thryothorus sinaloa and T. felix. Behav. Ecol. Sociobiol. 5, 111-131. doi:10.1007/BF00293301.

Brunton, D. H., Evans, B. A., and Ji, W. (2008). Assessing natural dispersal of New Zealand bellbirds using song type and song playbacks. N. Z. J. Ecol. 32, 147-154.

Catchpole, C. K. (1987). Bird song, sexual selection and female choice. Trends Ecol. Evol. 2, 94-97. doi:10.1016/0169-5347(87)90165-0.

Catchpole, C. K., and Slater, P. J. B. (2008). Bird song: Biological themes and variations. 2nd ed. New York, NY, US: Cambridge University Press doi:10.1017/CB09780511754791.

Clarke, A. L., Saether, B.-E., and Røskaft, E. (1997). Sex biases in avian dispersal: a reappraisal. Oikos, 429-438. doi:10.2307/3546885.

Clarke, K. R., and Gorley, R. N. (2015). PRIMER v7: User Manual/Tutorial. PRIMEREPlymouth.

Colwell, R. (2013). EstimateS: Statistical estimation of species richness and shared species from samples. Available at: http://purl.oclc.org/estimates.

Darwin, C. (1871). The descent of man and selection in relation to sex. London: John Murray.

Dawkins, R. (1976). The selfish gene. Oxford University Press.

Dixon, W. J., and Mood, A. M. (1946). The Statistical Sign Test. J. Am. Stat. Assoc. 41, 557566. doi:10.1080/01621459.1946.10501898.

Dooling, R. (2004). "Audition: can birds hear everything they sing?," in Nature's Music (Elsevier), 206-225. doi:10.1016/B978-012473070-0/50010-4.

Duda, R. O., Hart, P. E., and Stork, D. G. (2012). Pattern classification. John Wiley \& Sons.

Evans, C., and Kleindorfer, S. (2016). Superb fairy-wren (Malurus cyaneus) sons and daughters acquire song elements of mothers and social fathers. Front. Ecol. Evol. $4,9$.

Feekes, F. (1977). Colony-specific song in Cacicus cela (Icteridae, Aves) - password hypothesis. Ardea 65, 197-202.

Fukuzawa, Y., Webb, W. H., Pawley, M. D. M., Roper, M. M., Marsland, S., Brunton, D. H., et al. (2020). Koe: Web-based software to classify acoustic units and analyse 
sequence structure in animal vocalizations. Methods Ecol. Evol. 11, 431-441. doi:10.1111/2041-210X.13336.

Graham, B. A., Heath, D. D., and Mennill, D. J. (2017a). Dispersal influences genetic and acoustic spatial structure for both males and females in a tropical songbird. Ecol. Evol. 7, 10089-10102. doi:10.1002/ece3.3456.

Graham, B. A., Heath, D. D., and Mennill, D. J. (2021). Female and male song exhibit both parallel and divergent patterns of cultural evolution: A long-term study of song structure and diversity in tropical wrens. Ornithology 138. doi:10.1093/ornithology/ukaa067.

Graham, B. A., Heath, D. D., Walter, R. P., Mark, M. M., and Mennill, D. J. (2018a). Parallel evolutionary forces influence the evolution of male and female songs in a tropical songbird. J. Evol. Biol. 31, 979-994. doi:10.1111/jeb.13279.

Graham, B. A., Heath, D. D., Walter, R. P., and Mennill, D. J. (2018b). Immigrant song: males and females learn songs after dispersal in a tropical bird. Behav. Ecol. 29, 711-723. doi:10.1093/beheco/ary029.

Graham, B. A., Sandoval, L., Dabelsteen, T., and Mennill, D. J. (2017b). A test of the Acoustic Adaptation Hypothesis in three types of tropical forest: degradation of male and female Rufous-and-white Wren songs. Bioacoustics 26, 37-61. doi:10.1080/09524622.2016.1181574.

Greenwood, P. J. (1980). Mating systems, philopatry and dispersal in birds and mammals. Anim. Behav. 28, 1140-1162. doi:10.1016/S0003-3472(80)80103-5.

Hall, M. L. (2000). The function of duetting in magpie-larks: conflict, cooperation, or commitment? Anim. Behav. 60, 667-677. doi:10.1006/anbe.2000.1517.

Hall, M. L., Rittenbach, M. R. D., and Vehrencamp, S. L. (2015). Female song and vocal interactions with males in a neotropical wren. Behav. Evol. Ecol. 3, 12. doi:10.3389/fevo.2015.00012.

Hamers, L., Hemeryck, Y., Herweyers, G., Janssen, M., Keters, H., Rousseau, R., et al. (1989). Similarity measures in scientometric research: The Jaccard index versus Salton's cosine formula. Inf. Process. Manag. 25, 315-318. doi:10.1016/03064573(89)90048-4.

Heather, B. D., and Robertson, H. A. (2000). The field guide to the birds of New Zealand. Viking \Penguin Books.

Hill, S. D., Brunton, D. H., Anderson, M. G., and Ji, W. (2018). Fighting talk: complex song elicits more aggressive responses in a vocally complex songbird. Ibis 160, 257268.

Illes, A. E. (2014). Context of female bias in song repertoire size, singing effort, and singing independence in a cooperatively breeding songbird. Behav. Ecol. Sociobiol., 1-12. doi:10.1007/s00265-014-1827-3. 
Irwin, D. E., Bensch, S., Irwin, J. H., and Price, T. D. (2005). Speciation by distance in a ring species. Science 307, 414-416. doi:10.1126/science.1105201.

Janik, V. M., and Slater, P. J. (1997). Vocal learning in mammals. Adv. Study Behav. 26, 59100.

Jenkins, P. F. (1978). Cultural transmission of song patterns and dialect development in a free-living bird population. Anim. Behav. 26, 50-78. doi:10.1016/00033472(78)90007-6.

Kroodsma, D., Hamilton, D., Sánchez, J. E., Byers, B. E., Fandiño-Mariño, H., Stemple, D. W., et al. (2013). Behavioral Evidence for Song Learning in the Suboscine Bellbirds (Procnias spp.; Cotingidae). Wilson J. Ornithol. 125, 1-14. doi:10.1676/12-033.1.

Lachlan, R. F., Verzijden, M. N., Bernard, C. S., Jonker, P.-P., Koese, B., Jaarsma, S., et al. (2013). The progressive loss of syntactical structure in bird song along an island colonization chain. Curr. Biol. 23, 1896-1901. doi:10.1016/j.cub.2013.07.057.

Lande, R. (1980). Sexual dimorphism, sexual selection, and adaptation in polygenic characters. Evolution 34, 292-305. doi:10.2307/2407393.

Levin, R. N. (1996). Song behaviour and reproductive strategies in a duetting wren, Thryothorus nigricapillus: I. Removal experiments. Anim. Behav. 52, 1093-1106. doi:10.1006/anbe.1996.0257.

Logue, D. M., Droessler, E. E., Roscoe, D. W., Vokey, J. R., Rendall, D., and Kunimoto, R. M. (2007). Sexually antithetical song structure in a duet singing wren. Behaviour 144, 331-350. doi:10.1163/156853907780425749.

Mann, N. I., Dingess, K. A., Barker, F. K., Graves, J. A., and Slater, P. J. B. (2009). A comparative study of song form and duetting in neotropical Thryothorus wrens. Behaviour 146, 1-43.

Mennill, D. J., and Rogers, A. C. (2006). Whip it good! Geographic consistency in male songs and variability in female songs of the duetting eastern whipbird Psophodes olivaceus. J. Avian Biol. 37, 93-100. doi:10.1111/j.0908-8857.2006.03548.x.

Mennill, D. J., and Vehrencamp, S. L. (2005). Sex differences in singing and duetting behavior of neotropical rufous-and-white wrens (Thryothorus rufalbus). The Auk 122, 175-186. doi:10.1642/0004-8038(2005)122[0175:SDISAD]2.0.C0;2.

Odom, K. J., Hall, M. L., Riebel, K., Omland, K. E., and Langmore, N. E. (2014). Female song is widespread and ancestral in songbirds. Nat. Commun. 5. doi:10.1038/ncomms4379.

Paris, D., Nicholls, A. O., Hall, A., Harvey, A., and Massaro, M. (2016). Female-biased dispersal in a spatially restricted endemic island bird. Behav. Ecol. Sociobiol. 70, 2061-2069. doi:10.1007/s00265-016-2210-3. 
Parker, K. A., Anderson, M. J., Jenkins, P. F., and Brunton, D. H. (2012). The effects of translocation-induced isolation and fragmentation on the cultural evolution of bird song. Ecol. Lett. 15, 778-785. doi:10.1111/j.1461-0248.2012.01797.x.

Paton, J. A., Manogue, K. R., and Nottebohm, F. (1981). Bilateral organization of the vocal control pathway in the budgerigar, Melopsittacus undulatus. J. Neurosci. 1, 12791288.

Podos, J., and Warren, P. S. (2007). "The evolution of geographic variation in birdsong," in Advances in the Study of Behavior, eds. H. J. Brockmann, T. J. Roper, M. Naguib, K. E. Wynne-Edwards, C. Barnard, and J. Mitani (Academic Press), 403-458. Available at: http://www.sciencedirect.com/science/article/pii/S0065345407370095.

Poole, J. H., Tyack, P. L., Stoeger-Horwath, A. S., and Watwood, S. (2005). Animal behaviour: elephants are capable of vocal learning. Nature 434, 455.

Potvin, D. A., and Clegg, S. M. (2015). The relative roles of cultural drift and acoustic adaptation in shaping syllable repertoires of island bird populations change with time since colonization. Evolution 69, 368-380. doi:10.1111/evo.12573.

Price, J. J. (2015). Rethinking our assumptions about the evolution of bird song and other sexually dimorphic signals. Behav. Evol. Ecol. 3, 40. doi:10.3389/fevo.2015.00040.

Riebel, K., Lachlan, R. F., and Slater, P. J. B. (2015). "Chapter Six - Learning and Cultural Transmission in Chaffinch Song," in Advances in the Study of Behavior, eds. M. Naguib, H. J. Brockmann, J. C. Mitani, L. W. Simmons, L. Barrett, S. Healy, et al. (Academic Press), 181-227. doi:10.1016/bs.asb.2015.01.001.

Riebel, K., Odom, K. J., Langmore, N. E., and Hall, M. L. (2019). New insights from female bird song: towards an integrated approach to studying male and female communication roles. Biol. Lett. 15, 20190059.

Roper, M. M. (2018). Sexual dimorphism of song and life history trade-offs in the New Zealand bellbird: a thesis presented in partial fulfilment of the requirements for the degree of Doctor of Philosophy (Ph. D.) in Ecology at Massey University, Albany, New Zealand.

Roper, M. M., Harmer, A. M. T., and Brunton, D. H. (2018). Developmental changes in song production in free-living male and female New Zealand bellbirds. Anim. Behav. 140, 57-71. doi:10.1016/j.anbehav.2018.04.003.

Sanvito, S., Galimberti, F., and Miller, E. H. (2007). Observational evidences of vocal learning in southern elephant seals: a longitudinal study. Ethology 113, 137-146. doi:10.1111/j.1439-0310.2006.01306.x.

Sayigh, L. S., Esch, H. C., Wells, R. S., and Janik, V. M. (2007). Facts about signature whistles of bottlenose dolphins, Tursiops truncatus. Anim. Behav. 74, 1631-1642. doi:10.1016/j.anbehav.2007.02.018. 
Sokal, R. R. (1958). A statistical method for evaluating systematic relationship. Univ. Kans. Sci. Bull. 28, 1409-1438.

Tobias, J. A., Montgomerie, R., and Lyon, B. E. (2012). The evolution of female ornaments and weaponry: social selection, sexual selection and ecological competition. Philos. Trans. R. Soc. Lond. B Biol. Sci. 367, 2274-2293. doi:10.1098/rstb.2011.0280.

Webb, W. H., Brunton, D. H., Aguirre, J. D., Thomas, D. B., Valcu, M., and Dale, J. (2016). Female song occurs in songbirds with more elaborate female coloration and reduced sexual dichromatism. Front. Ecol. Evol. 4, 22.

Whitehead, H., and Rendell, L. (2014). The cultural lives of whales and dolphins. University of Chicago Press.

Wickler, W., and Seibt, U. (1980). Vocal duetting and the pair bond. Z. Für Tierpsychol. 52, 217-226. doi:10.1111/j.1439-0310.1980.tb00713.x.

Wickler, W., and Seibt, U. (1988). "Gender dialects" - a new phenomenon from birdsong epigenesis. Naturwissenschaften 75, 51-52. doi:10.1007/BF00367445. 
bioRxiv preprint doi: https://doi.org/10.1101/2021.07.05.451205; this version posted July 27, 2021. The copyright holder for this preprint (which was not certified by peer review) is the author/funder. All rights reserved. No reuse allowed without permission. 